with US Senator Hubert Humphrey professing horror at the prescription of meprobamate 'as freely as aspirin', or today, as British MPs jostle to condemn antidepressant prescription volumes, the careerist rhetoric remains the same.

Anyone picking up Shorter's book to enjoy a diatribe against the evil of antidepressants will be disappointed (NICE guidance is the place to go for that). His concerns lie with the paucity of effective drugs, not the principle of chemical treatment. But his assessment of the value of older therapies is not correct: opiates and alcohol are possibly not the best approach to mood disorder (though a fair proportion of the antidepressant-sceptical 'public' seem keen), whereas the serendipitously discovered antidepressants and their descendants were never wholly effective despite the advance they represented. The monoamine hypothesis that grew as drug mechanisms were unravelled could never be adequate either. Mundane commercial conservatism was responsible for the raft of 'me-too' agents that followed: industry simply got on with making products to sell. Academic psychiatry did not have the technology or the ideas to contribute anything new, and got on with making an increasingly fine-grained but futile map of the monoamine system. A sufficiently sophisticated neuroscience of mood disorder just does not exist to guide rational drug development. Possibly it is beginning to emerge now, from interplay between the realms of molecular biology, imaging and neuropsychology. But it may be too late, as it was for Charlton Heston, emerging dumbfounded from a crashed spacecraft to discover that his planet had been taken over by an advanced but brutish civilisation of cognitive therapists. (My memory of plot detail may be a little hazy here.)

The hyperbolic blurb on the back cover would have you believe that this book is a revelatory work of Kuhnian stature. It is not. But it is engaging, sprinkled with Chandleresque dialogue - FDA agents say things like, 'Baby, it ain't gonna happen' and 'your products are toast' - and fun: you will learn that Leandro Panizzon (who synthesised methylphenidate) named his drug 'Ritalin' after his wife Rita because she liked to take it before tennis matches. And that a horse named Marsilid (after the first monoamine oxidase inhibitor used in depression) won in the 9th at Belmont in 1949 (perhaps it was cheating too).

I would recommend the book as solid summer holiday reading: but don't just continuously develop professionally on the beach - bid for the film rights.

Ian Reid University of Aberdeen, Cornhill Hospital, Aberdeen AB25 2ZH. Email: ian.reid@btinternet.com

doi: 10.1192/bjp.bp. 109.064196

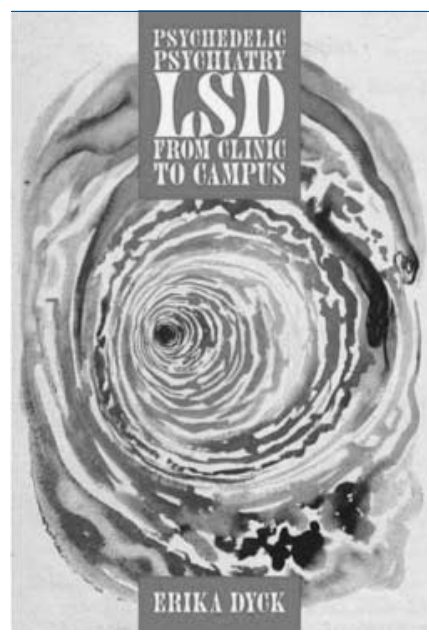

By Erika Dyck.

Johns Hopkins University Press. 2008. US\$35.00 (hb). 216pp. ISBN: 9780801889943

\section{Psychedelic Psychiatry: LSD from Clinic to Campus}

Psychedelic psychiatry was a topic I knew little of. The use of lysergic acid diethylamide (LSD) in treating mental illness seemed an alien and somewhat dangerous concept. I was interested to see what emerged from this historical review of these practices in North America in the 1950s and '60s. The author, an assistant professor in history, narrates the real life events from the perspective of the two main protagonists, Humphry Osmond and Abram Hoffer. Osmond was a British psychiatrist who trained at Guy's and Hoffer was an American psychiatrist. They were kindred spirits, both biologically minded in their approach to treatment. The story of psychedelic psychiatry and LSD is told as if it was intertwined with their professional fates.

The book reads like a tragedy. There is initially much hope and enthusiasm that LSD could lead to major breakthroughs in understanding the biological basis of mental illness. There were hugely promising results from trials. Hoffer and Osmond appear as pioneers on the edge of a great leap in psychiatric treatment through the use of LSD. But as with tragedies, LSD, psychedelic psychiatry and the two main characters suffer repeated blows. The psychiatric world becomes reluctant to acknowledge the results, for various reasons. Increasingly desperate to make their mark, Hoffer and Osmond seek other non-medical uses of LSD such as aiding self-realisation and spirituality. This alienates them further and leads to the journey of LSD from clinic to campus. The 'tragedy' ends with LSD becoming increasingly used illicitly. Eventually, this leads to statutory legislation that heavily restricts and stigmatises its clinical use. Thus, LSD, psychedelic psychiatry and the two main characters are pushed to the backwaters of psychiatry.

The story is very well written and researched, allowing the reader to have empathy for the two psychiatrists through the highs and lows of their journey. Along the way the author gives fascinating insights into conflicts within psychiatry. She also illustrates how societal views and politics can influence the development of psychiatric treatments. Overall, the book is a good read and has the bonus of imparting historical understanding of psychiatry during its most exciting and innovative era.

Sanjay K. Khurmi Birmingham and Solihull Mental Health Trust, Highcroft Hospital 411 Slade Road, Erdington, Birmingham B23 7LA, UK. Email: skhurmi@hotmail.com

doi: 10.1192/bjp.bp.109.064121

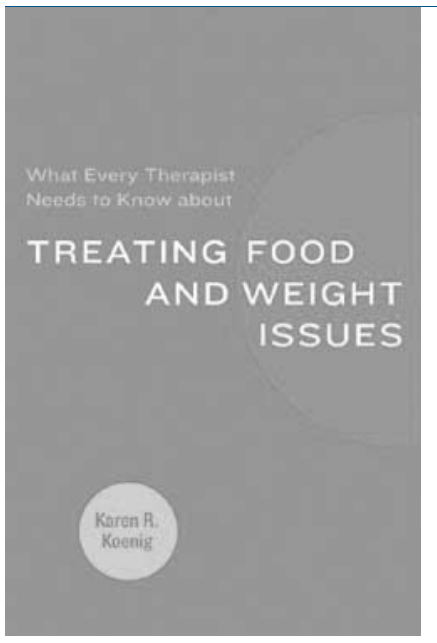

\section{What Every Therapist Needs to Know about Treating Food and Weight Issues}

By Karen R. Koenig. W. W. Norton. 2008. US $\$ 25.00$ (pb). 256pp ISBN: 9780393705584

This is a short and initially engaging book written in an informal style. Its purpose is to help non-specialists 'gain confidence and competence in assessing and treating weight and eating issues' 
(p. 7). Cognisant of the growing number of those with 'overweight and obesity', it is refreshing to see a clinician guide that attempts to address emotional and physical issues found in both weight and eating disorders.

The reader, however, has a rather meandering journey through the early chapters before reaching some that move beyond encouraging personal reflections to more direct advice about how to assess and treat eating and weight issues. There are some pearls here but it is difficult at times to find them among rather less helpful information. Hidden within several of the first chapters is the reasonable thesis that the obesity epidemic and subsequent health risks may well be overstated and the most helpful advice concerning a fit and healthy, albeit mildly or moderately overweight, person is that he or she is well and requires no specific intervention. At one point medical practitioners are gently remonstrated to reflect on how patients might feel when asked to be weighed, especially when done 'opportunistically' during a consultation for an unrelated issue.

However, some areas are problematic, particularly the final chapter on treatment where evidence-based therapies such as cognitive-behavioural therapy are accorded the same (or even less) emphasis as other treatments with much less to recommend them (e.g. gestalt therapy). The high reliance on internet-based sources and self-help information as well as the conversational style perhaps set the scene. The book wisely closes with encouragement for the therapist 'not to be afraid' to make a referral to a specialist.

This book is an introduction to eating and weight issues for the undifferentiated practitioner who treats people at the 'not otherwise specified' end of the eating and weight disorders spectrum. It is not an authoritative text and it is not for those managing morbidly obese or severely underweight individuals, or those with even moderately severe bulimia. (A 'further reading' section would have been good in this regard.) Still, it encourages a high degree of personal reflection and integration of one's own views and biases around eating and weight issues, which is helpful to those naive to the area.

Phillipa Hay Foundation Chair of Mental Health, School of Medicine, University of Western Sydney, Campbelltown Campus, Locked Bag 1797, Sydney 1797, Australia. Email: p.hay@uws.edu.au

doi: 10.1192/bjp.bp.108.061523

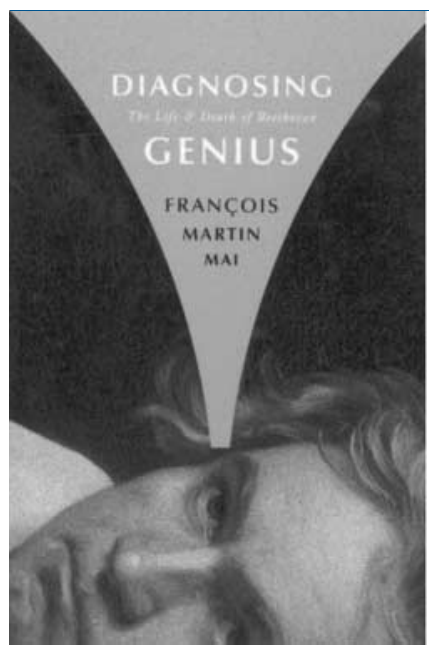

\section{Diagnosing Genius. The Life and Death of Beethoven}

By François Martin Mai. McGill-Queen's University Press 2007. US\$29.95 (hb). 288pp. ISBN: 9780773531901

It is lucky for us that Ludwig van Beethoven was more well-known than most during his lifetime as much more information about his life (and death) survives as a consequence. François Martin
Mai, Professor of Psychiatry at Ottawa Hospital, has meticulously analysed all the existing material and provides a revealing insight into the life and death of Beethoven and how his health and state of mind affected his music.

Beethoven was a prolific letter-writer - over 1500 of his letters are still in existence, from which Professor Mai has extracted every reference to Beethoven's numerous medical conditions and considers them in the minutest detail, splitting them into the various affected systems. In addition, he supplies absorbing tables denoting each medical problem and which letter it is from, and lists them all chronologically. Intriguingly, there are more references to Beethoven's mental health in his letters than any other ailments, even deafness. In 1802 he considered suicide but wrote that 'It seemed impossible to leave this world before I had produced all the works I felt the urge to compose'.

Beethoven's 'conversation books' (which are the actual written 'conversations' used to communicate with him towards the end of his life after profound deafness had descended) are also consulted. These are truly unique and, as Mai points out, they are 'of special interest as some of the very few verbatim reports of doctor-topatient communication we have from the pre-electronic era'. The extracts from these books are simply riveting. The author even provides his own new translation of the autopsy report (originally in Latin) as well as some wonderful plates and comprehensive appendices. The final compelling chapter discusses the links between mental state, physical illness and creativity, drawing on Mai's vast experience as both psychiatrist and musician.

Diagnosing Genius is not only exhaustively researched and authoritatively written, it also provides an extraordinary snapshot of the world of medicine during Beethoven's life, composed in layman's terms that will appeal to an enormously wide audience.

Daniel Tomkins Royal College of Psychiatrists, 17 Belgrave Square, London SW1X 8PG, UK. Email: dtomkins@rcpsych.ac.uk

doi: 10.1192/bjp.bp.109.063826

\section{DNVID GARHLL AND DANII MACKUR \\ Beyond Medication: Therapeutic Engagement and the Recovery \\ Beyond Medication from Psychosis}

Edited by David Garfield \& Daniel Mackler. Routledge. 2008 £19.99 (pb). 216pp. ISBN: 9780415463874

Beyond Medication contains many impressive case descriptions in which psychotherapists discuss their treatment of individuals with psychotic disorders. Various chapters show how the authors have put great amounts of time and effort into treatments for, sometimes, relatively small improvements. Two chapters are written by former patients and there is also a chapter discussing a survey of patients' experiences of drug treatment.

The overriding aim of Beyond Medication is to argue against the dominant position of pharmacological treatment of psychotic 